\title{
Cisgender Commonsense and Philosophy's Transgender Trouble
}

ROBIN DEMBROFF

Abstract Analytic philosophy has transgender trouble. In this article, the author explores potential explanations for this trouble, focusing on the notion of "cisgender commonsense" and its place in philosophical methodology.

Keywords philosophy, analytic philosophy, feminist philosophy, philosophy of gender

I just want to know the ordinary view [of gender].

-Unnamed philosophy professor

\begin{abstract}
A nalytic philosophy has transgender trouble. ${ }^{1}$ Many readers are likely aware of the controversy surrounding Rebecca Tuvel's 2017 paper, "In Defense of Transracialism." But the Tuvel imbroglio is the tip of the iceberg. Those interested in further details can read Talia Bettcher's (2018) "When Tables Speak" or Samantha Hancox-Li's (2019) "Why Has Transphobia Gone Mainstream in Philosophy?" (see also Flaherty 2019). Both outline a disturbing and increasing pattern of antitrans rhetoric being uttered, endorsed, or excused by analytic philosophers. They could also read Gayle Salamon's (2009) “Justification and Queer Method; or, Leaving Philosophy” or Naomi Scheman's (1997) “Queering the Center by Centering the Queer" to situate this antitrans sentiment in the context of philosophy's historical prejudice against queerness. Or they could read Kristie Dotson's (2012) “How Is This Paper Philosophy?” to better understand philosophy's generally chilling environment for persons that Doston calls "diverse practitioners."

I'm daunted by the task of diagnosing analytic philosophers' seemingly incurable tendency to at best ignore transgender issues and, more recently, barge into them swinging. I've watched transgender graduate students leave philosophy
\end{abstract}


rather than cope with coming out in it. I've had my research mansplained to me by philosophers who hadn't read a single piece of gender theory. I've been asked in Q\&A why gender is a philosophical topic. I've been informed that I was passed up for a job because I am transgender. As a graduate student, a senior faculty member told me to my face that he would not use my pronouns because they are "ungrammatical." More generally, I'm constantly aware of philosophers who take to social media and blogs to forcefully opine about trans people from a place of complete ignorance. Using dog whistles and misinformation in addition to philosophical tools, these philosophers spend their time and talents on creating more sophisticated versions of dominant gender ideology. They then wield this ideology nearly exclusively against trans persons. Maybe worse, I've heard colleagues - many, well meaning - rise to the defense of this behavior in the name of "academic freedom."

The situation in philosophy is, to be blunt, a massive, complex, and thorny transgender trashfire. This trashfire manifests most explicitly in the context of social media, blogs, interpersonal interactions, and the occasional journal publication, and it has serious repercussions. (To name one, a number of high-profile court briefings opposing trans rights in both the United States and the United Kingdom cite blog posts by philosophers such as Kathleen Stock and Alex Byrne as evidence that trans persons are dangerous and deluded.) $)^{2}$ I hope to show that it also manifests in the very methods and views that are considered philosophically legitimate, and how they are related to philosophy's long-standing troubles with race, class, disability, and gender more broadly.

While reflecting on philosophy's transgender trashfire, I found myself repeatedly coming back to a particular memory. Near the end of my first semester of graduate school, I brought a draft of my metaphysics term paper to my professor's office hours. I was writing on the philosophy of time but had run up against a problem with my argument. After explaining this problem, I assured my professor that I would read more of the relevant literature to make progress on a solution. Eight years later, I still clearly remember what happened next. My professor leaned forward and pushed the draft back to me. "Don't read," he said. "Go think!" I hold a lot of affection for that professor. But reflecting on these four words - Don't read: go think — helped me make headway on the question, why does analytic philosophy have transgender trouble?

First, I should admit that I am a pluralist by philosophical disposition. More often than not, I think that philosophical questions have multiple legitimate answers. In my own work, this means that I defend polysemy about gender terms and context-specific pluralism about gender categories. With respect to the metaphilosophical question of why philosophy has transgender trouble, I'm again disposed to pluralism: there are many legitimate answers. After all, the world has 
transgender trouble. Philosophers have the same problems as everyone else and (I'd argue) a few extra to boot. So I want to reframe the question: are there unique features of analytic philosophy that at least partially explain why it has transgender trouble? In considering this question, my first thought was about the demographics of philosophy. Who, historically and at present, counts as a philosopher? Whose works are considered "paradigms" of philosophical inquiry? Who establishes philosophy's dominant imaginary-the shared assumptions, values, and beliefs that give rise to prevailing conventions, rules, and practices within our discipline?

No one will be shocked to know that philosophy long has been the dominion of (almost exclusively) men who perched atop nearly every imaginable social hierarchy. Even now, in 2020, it's common for a philosophy syllabus to be composed entirely of cisgender, straight-identified, white men from the global North. One effect is that socially dominant interests, standpoints, and modes of thought saturate philosophy's center. But beyond that, philosophy also has a longstanding tradition of using philosophical methods and tools for the purpose of justifying these social hierarchies. As Christia Mercer (2019) convincingly argues, the history of philosophy is filled with men using philosophical reasoning to justify their presupposition that women are inferior-morally and bodily- to men. Similarly, Charles Mills (1997) points out that philosophy is hostile to persons of color, as well as to discussions of concrete sociopolitical issues such as reparations, colonialism, and racism. The reason, Mills argues, is that white philosophers set up disciplinary boundaries that count these people and ideas as incompatible with "serious philosophy" (4). Similar arguments could be made regarding disability, class, ethnicity, sexual orientation, and, importantly for our purposes, gender identity. Transgender persons and issues have been not only missing from philosophy but systematically excluded by philosophers who use their training to justify dominant ideology about sex and gender, and who dismiss challenges to this ideology as unjustified, irrational, unreasonable, or (my personal favorite) counterintuitive. ${ }^{3}$

But this isn't yet a satisfying explanation. The overwhelming cis, straight, nondisabled whiteness of philosophy is important, but it isn't — at least, not historically-unique to philosophy. The academy long has been the stomping grounds of privileged white men. And while every field has problems, I regularly hear colleagues from other humanities disciplines express horror at the carelessness, cruelty, and ignorance on display in philosophers' public discussions of transgender issues. There remains an explanatory gap between the fact of philosophy's cisgenderness and the fact that philosophy can be and is used to devalue trans persons.

Talia Bettcher (2018) suggests a source of philosophy's transgender trouble that is somewhat orthogonal to its demographics. "It's more than a little 
heartbreaking," she writes, "to find an entire literature, a rich domain of philosophy, all of one's own hard work, completely erased-due to nothing but arrogance, dismissiveness, and laziness." While I agree with Bettcher, I still feel some dissatisfaction with this answer. Laziness, to me, suggests a blameworthy failure to care about the tasks or norms that one is expected to satisfy. I do not think philosophers are intellectually lazy in this respect. Philosophers are not irresponsibly failing to meet an expectation to engage existing philosophical (much less interdisciplinary) work on gender before opining about it. ${ }^{4}$ There is no such expectation, particularly within my specialization, the subfield of metaphysics. ${ }^{5}$

Given this, it is predictable that philosophers who speak from ignorance about trans issues - and, typically, the metaphysics of gender specificallynegatively react to charges of laziness and hubris. These charges, to them, can seem like accusing a soccer player of double dribbling; for many, the operating rules of philosophy don't say that one must be informed about the literature on a topic prior to "doing philosophy" about it. It is no wonder, then, that when feminist, queer, and trans scholars charge these philosophers with intellectual laziness and hubris, we are countered with the allegation that we are "zealots" and "tin pot dictators" who are waging war against academic freedom. ${ }^{6}$ Within philosophy, ignorant speech on trans issues is not generally perceived as lazy or arrogant (though I agree with Bettcher that, relative to broader scholarly norms, it is). To the contrary, it is considered academic speech, as opposed to speech uttered by persons who happen to be academics. It is considered philosophically serious speech.

Here again, we can ask: why? I suspect that an answer lies somewhere both between and below philosophy's cisgenderness and its intellectual laziness and hubris. The first part of the answer brings us back to the advice to "go think" rather than read. Thinking - and speaking — before reading is not merely tolerated in philosophy; it is advised. At the very least, it is assumed a standard way of doing serious and original philosophical work. Five minutes of reflection will tell us that this methodology creates a disciplinary culture in which so-called commonsense is self-justifying and universalized. Stephanie Kapusta helpfully summarizes philosophy's methodological reliance on commonsense as reliance on "clear, independent analysis" of presupposed concepts or terms, in which the targeted concepts or terms are "decomposed . . . into simpler units."7 These presupposed concepts and terms are not only abstracted away from history and social context - they establish the boundaries around which views are philosophically serious. ${ }^{8}$ Philosophical work is devoted to making presupposed concepts and terms precise, consistent, or explanatorily useful, and only rarely to challenging them or questioning the entire conceptual framework on which they rest. This methodology is philosophically legitimate, by which I mean it is 
generally accepted as a method for producing philosophical knowledge (or, at least, justified philosophical beliefs). ${ }^{9}$ The philosophical legitimacy of thinking (and speaking) without reading - and, more to the point, of commonsense methodology — can help us understand why philosophers are permitted to speak ignorantly about trans issues, and do so with impunity. It also helps us understand why their speech generally takes dominant gender ideology for grantedagain, with impunity. (After all, as Sally Haslanger [2017] among others have pointed out, a central tool of ideology is to pass itself off as commonsense.)

But this does not, by itself, wholly account for philosophy's transgender trouble. In particular, it does not explain two things: first, philosophy's general hostility toward transgender identifications and experiences, and second, its intolerance for those philosophers (primarily, feminist philosophers) whose intuitions clash with what we might call "cisgender commonsense" - the presupposed concepts and terms built into dominant, trans-exclusive gender ideology.

To account for this hostility and intolerance, we have to ask a further series of questions: Whose commonsense constitutes philosophically legitimate commonsense? Whose pretheoretical concepts and terms constrain philosophical inquiry? And whose intuitions are philosophical intuitions? It isn't simply that "Don't read—go think!" is a legitimate methodology within philosophy; it is legitimate only when the resulting thoughts adequately align with the commonsense of the culturally powerful. ${ }^{10}$ By contrast, the commonsense of the racialized, poor, queer, transgender, or disabled is considered philosophically irrelevant "ideology," "activism," or "delusion." Their perspectives are automatically placed in what Salamon (2009: 228) calls the "realm of justification": in this realm, an unmeetable epistemological burden to prove their philosophical legitimacy is placed on already marginalized people and ideas. Speaking about a job interviewer's demand, years prior, that she justify her work on queerness as philosophical work, Salamon writes, "I am still not sure what kind of justification might have sufficed" (229).

I share Salamon's exasperation. No justification for trans philosophy will suffice when alignment with cisgender commonsense is necessary for work to be considered philosophical work. Not that justifications aren't available: a cursory search would turn up books, academic journals, and even popular articles that discuss the methodology of feminist, queer, and transgender philosophy. But this literature is brushed aside as politically motivated, unlike the objective and rational perspective of cisgender philosophers who have mastered the methodology of thinking without reading.

Excuse the sarcasm; I'm exasperated. My point, in short, is that uninformed (they would say "a priori”) thought about trans issues is deemed philosophical only when it aligns with cisgender commonsense. What seems intuitive 
to gender-conforming philosophers who have never studied trans and queer scholarship sets the standards for what counts as legitimate, "objective" philosophical positions about trans issues. And this situation is not unique to trans issues: similar standards historically have ruled out the possibility of analytic philosophy of race, gender, disability, or class, as well as social critique more generally. While highly abstract arguments about the ideal form of justice are considered paradigmatically philosophical, ${ }^{11}$ empirically informed arguments about local forms of racial justice are devalued as "lightweight" philosophy. ${ }^{12}$ While the nature of mental content is assumed to clearly be a philosophical issue, the nature of gender identity is not. While philosophical debate over the source of happiness traces back to Aristotle, relevant insights from disability studies about well-being have been ignored. The list goes on and on.

To make this point concrete, let me describe a scene. In spring 2018, I gave a paper on genderqueer identification at a prestigious philosophy department. At the end of my talk, a senior faculty member asked the first question: "What do you think gender is?" I responded by explaining my pluralist stance on this question. He was not satisfied. "I just want to know the ordinary view," he said. "Ordinary for whom?" I replied. "Just the ordinary view," he insisted. "I honestly don't understand your question," I said. "Ordinary for whom?" He grew frustrated. "Just the ordinary view! What someone in the pub would say."

The fact that, to this philosopher, an anonymous cisgender person in a bar is an authority on gender speaks volumes. Even more does the fact that, in the space of an academic talk, it was unremarkable to presuppose not only that the socalled ordinary view is philosophically authoritative, but also that the ordinary view is the estate of persons who have never reflected on, much less lived, transgender or queer experience. In this story, we see the combination of both "Don't read—go think!" as a philosophically legitimate methodology, as well as the presupposition that cisgender commonsense sets the limits on what views about gender are immune from the otherwise inescapable "realm of justification." Analytic philosophy's transgender trouble will remain so long as philosophers continue to disregard trans studies and voices, and undeservedly legitimize cisgender commonsense.

Robin Dembroff is assistant professor of philosophy at Yale University. Their research focuses on feminist metaphysics, epistemology, and philosophy of language.

\section{Acknowledgments}

Many thanks to Elizabeth Barnes, Katharine Jenkins, Stephanie Kapusta, Laurie Paul, Jennifer Saul, and Susan Stryker for feedback during the development of this article. 


\section{Notes}

1. My focus is on analytic philosophy, which is rooted and predominant in anglophone philosophy departments. Analytic philosophy is commonly (though not without difficulty) distinguished from continental philosophy, in which central figures (e.g., Foucault, Hegel, Heidegger, Derrida, Merleu-Ponty) typically come from mainland Europe and employ different analytical tools and methods than analytic philosophers. See Gutting 2012 for a critical survey of various proposed bases for the analytic/continental distinction.

2. See, for example, multiple amicus briefs in the case of $R G \& G R$ Harris Funeral Homes $v$. Aimee Stephens that cite Kathleen Stock (Carter 2019; McHugh 2019). In addition, Maya Forstater's (2019) witness statement in a recent UK case cites Kathleen Stock, Alex Byrne, and Jane Clare Jones, as well as an Inside Higher Ed open letter from twelve philosophers that defended philosophers' antitrans rhetoric in the name of "academic freedom."

3. "Whose intuitions?" is the obvious next question.

4. At a minimum, I think philosophers should engage the existing literature on gender within philosophy before confidently opining about it. Arguably, they also should engage relevant literature outside philosophy as well, such as literature from sociology, history, anthropology, and gender studies.

5. I think metaphysics is here joined by epistemology and philosophy of language. Other subfields, such as modern and ancient philosophy, seem to be far less susceptible to legitimizing this methodology.

6. These are terms actually used by senior philosophy faculty (Brian Leiter and Daniel Kaufman) to describe Susan Stryker, Rebecca Kukla, and myself in response to our decision to not coplatform with antitrans activists (Dembroff, Kukla, and Stryker 2019; Leiter 2019; Kaufman 2019).

7. Kapusta, email correspondence to author, January 6, 2020.

8. Katharine Jenkins (2014: 263) points out that this leaves feminist philosophers in a double bind, as their "research will involve violating, to some degree, the norms of the very institution that makes it possible for [them] to undertake that research in the first place."

9. Here I draw from Dotson (2012: 5), who defines legitimization as "practices and processes aimed at judging whether some belief, practice, and/or process conforms to accepted standards and patterns, i.e. justifying norms."

10. Here, some might object that many philosophical positions are far from commonsensical — for example, David Lewis's modal realism, Peter Singer's hard-line consequentialism, Kant's transcendental idealism, and so on. I have two things to say in response to this objection. First, in all these cases, these noncommonsensical positions were derived from commonsense intuitions. That is, they are-according to their advocates-necessary consequences of what are taken as incorrigible commonsense intuitions, such as commitment to the possibility of things being other than they actually are, moral intuitions, and human free will. Second, and relatedly, even within philosophy, not all commonsense beliefs and attitudes are taken as equal. Some are seen as more fundamental than others. When these beliefs and attitudes internally conflict, or conflict with received information, philosophers often disagree about what to hold fixed and what to give up. It is perhaps especially damning then, to see that "commonsense" ideas about gender are so fundamental to many philosophers that they are willing to disregard the scholarly merits of entire fields of study to maintain them.

11. The term ideal form is intentional, as well as skeptical. See Mills 1997. 
12. See, for example, the exclusion of W. E. B. Du Bois, Frederick Douglas, and Angela Davis from the philosophical canon.

\section{References}

Bettcher, Talia Mae. 2018. "When Tables Speak: On the Existence of Trans Philosophy.” Daily Nous (blog), May 30. dailynous.com/2018/05/30/tables-speak-existence-trans-philosophy-guest -talia-mae-bettcher/.

Dembroff, Robin, Rebecca Kukla, and Susan Stryker. 2019. "Retraction Statement by Robin Dembroff, Rebecca Kukla, and Susan Stryker." Changing How the World Thinks, August 26. iai.tv/articles/retraction-statement-by-robin-dembroff-rebecca-kukla-and-susan-stryker -auid-1256.

Carter, W. Burlette. 2019. "Brief of Amicus Curiae Professor W. Burlette Carter in Support of Petitioner." Harris Funeral Homes v. Stephens. No. 18-107. United States Supreme Court.

Dotson, Kristie. 2012. "How Is This Paper Philosophy?" Comparative Philosophy 3, no. 1: 3-29.

Flaherty, Colleen. 2019. "The Divide over Scholarly Debate over Gender Identity Rages On." Inside Higher Ed, July 19. www.insidehighered.com/news/2019/07/19/divide-over-scholarly -debate-over-gender-identity-rages.

Forstater, Maya. 2019. "Claimant's Witness Statement." Medium, November 22. medium.com /@MForstater/claimants-witness-statement-abeze8073b41.

Gutting, Gary. 2012. "Bridging the Analytic-Continental Divide." New York Times, The Stone (blog), February 19. opinionator.blogs.nytimes.com/2012/02/19/bridging-the-analytic -continental-divide/.

Hancox-Li, Samantha. 2019. "Why Has Transphobia Gone Mainstream in Philosophy?” Contingent Magazine, October 1. contingentmagazine.org/2019/10/o1/transphobia-philosophy/.

Haslanger, Sally. 2017. "I—Culture and Critique." Aristotelian Society Supplementary Volume 91, no. 1: 149-73. doi.org/10.1093/arisup/akxoo1.

Jenkins, Katharine. 2014. “'That's Not Philosophy': Feminism, Academia, and the Double Bind." Journal of Gender Studies 23, no. 3: 262-74. doi.org/10.1080/09589236.2014.909720.

Kaufman, Daniel. 2019. "Philosophy's Aspirant Tin-Pot Dictators." Electric Agora (blog), September 8. theelectricagora.com/2019/og/o8/philosophys-aspirant-tin-pot-dictators/.

Leiter, Brian. 2019. "Zealots Working Overtime Now to Shut Down Gender Critical Feminists." Leiter Reports: A Philosophy Blog, September 1. leiterreports.typepad.com/blog/2019/o9 /zealots-working-overtime-now-to-shut-down-gender-critical-feminists.html.

McHugh, Paul R. 2019. "Brief of Amicus Curiae Dr. Paul R. McHugh, M.D. Professor of Psychiatry in Support of Petitioner." Harris Funeral Homes v. Stephens. No. 18-107. United States Supreme Court.

Mercer, Christia. 2019. "The Philosophical Origins of Patriarchy." Nation, July 1. www.thenation .com/article/patriarchy-sexism-philosophy-reproductive-rights/.

Mills, Charles. 1997. The Racial Contract. Ithaca, NY: Cornell University Press.

Salamon, Gayle. 2009. "Justification and Queer Method; or, Leaving Philosophy." Hypatia 24, no. 1: $225-30$.

Scheman, Naomi. 1997. "Queering the Center by Centering the Queer: Reflections on Transsexuals and Secular Jews." In Feminists Rethink the Self, edited by Diana Meyers, 124-62. Boulder, CO: Westview.

Tuvel, Rebecca. 2017. "In Defense of Transracialism." Hypatia 32, no. 2: 263-78. onlinelibrary.wiley .com/doi/abs/10.1111/hypa.12327. 